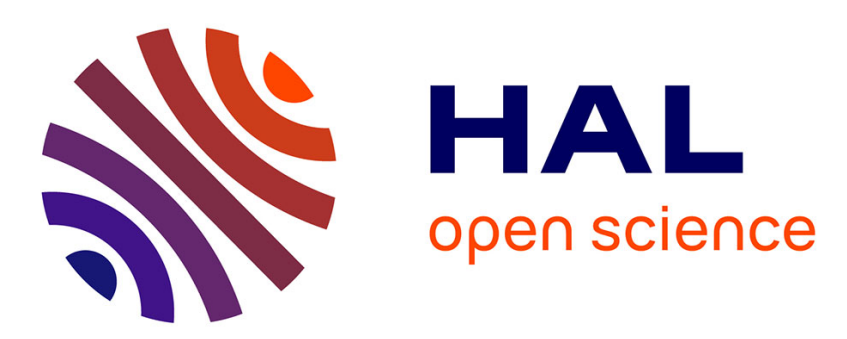

\title{
A COMPARISON OF THE HIGH STRAIN RATE BEHAVIOUR IN COMPRESSION OF POLYMERS AT $300 \mathrm{~K}$ AND 100K
}

S. Walley, John Field, N. Safford

\section{- To cite this version:}

S. Walley, John Field, N. Safford. A COMPARISON OF THE HIGH STRAIN RATE BEHAVIOUR IN COMPRESSION OF POLYMERS AT 300K AND 100K. Journal de Physique IV Proceedings, 1991, 01 (C3), pp.C3-185-C3-190. 10.1051/jp4:1991324 • jpa-00250466

\section{HAL Id: jpa-00250466 https://hal.science/jpa-00250466}

Submitted on 1 Jan 1991

HAL is a multi-disciplinary open access archive for the deposit and dissemination of scientific research documents, whether they are published or not. The documents may come from teaching and research institutions in France or abroad, or from public or private research centers.
L'archive ouverte pluridisciplinaire HAL, est destinée au dépôt et à la diffusion de documents scientifiques de niveau recherche, publiés ou non, émanant des établissements d'enseignement et de recherche français ou étrangers, des laboratoires publics ou privés. 


\title{
A COMPARISON OF THE HIGH STRAIN RATE BEHAVIOUR IN COMPRESSION OF POLYMERS AT 300K AND 100K
}

\author{
S.M. WALLEY, J.E. FIELD and N.A. SAFFORD \\ PCS Group, Cavendish Laboratory, Madingley Road, \\ GB-Cambridge CB3 OHE, Great-Britain
}

\begin{abstract}
Résumé - La réponse mécanique de plusieurs polymères ductiles d'utilisation courante a été étudiée en compression à des vitesses de déformation de $2,5 \times 10^{3} \mathrm{~s}^{-1}$, à température ambiante et dans l'azote liquide $(100 \mathrm{~K})$. Une barre d'Hopkinson à impact direct (BHID) est utilisée pour déterminer les courbes contrainte-déformation dans ces conditions d'expérimentation. La cinématographie ultra-rapide ( $7 \mu$ s entre images) est l'outil majeur pour déterminer la déformation à rupture, en particulier pour les polymères ayant une grande déformation à rupture, pour lesquels celles-ci n'apparaît pas dans la fenêtre de temps imposée par la BHID (285 $\mu$ s).
\end{abstract}

\begin{abstract}
The mechanical response of a number of widely used ductile polymers has been investigated in compression at strain rates of $c a .2 .5 \times 10^{3} \mathrm{~s}^{-1}$, both at room temperature (ca. 300K) and at liquid nitrogen temperatures (ca. 100K). A direct impact Hopkinson bar (DIHB) was used to measure the polymer stress-strain curves at this strain rate at both temperatures. High-speed photography (interframe time $7 \mu \mathrm{s}$ ) was a major tool in determining the fracture strain at both temperatures, particularly for those polymers that had such large failure strains that they did not fail within the time window of the DIHB $(285 \mu \mathrm{s})$.
\end{abstract}

\section{Introduction}

In previous studies /1-4/ of the high rate of deformation behaviour of a range of polymers in compression at room temperature $(\mathrm{ca} .300 \mathrm{~K})$, we determined (i) the best lubricant for such testing (vaseline), (ii) flow stresses over a wide strain-rate range $\left(10^{-2} \mathrm{~s}^{-1}\right.$ to $\left.10^{4} \mathrm{~s}^{-1}\right)$, (iii) failure strains of those that are brittle, and (iv) temperature rises associated with fracture and adiabatic rapid deformation. We also carried out a thorough investigation of sources of error in compression testing, including calibration errors, friction, inertia, and anvil indentation.

In this present paper, we report the effects of cooling to liquid nitrogen temperatures $(c a .100 \mathrm{~K})$ on the high strain rate (ca. $\left.2.5 \times 10^{3} \mathrm{~s}^{-1}\right)$ properties of those polymers which were either fully ductile or which exhibited a large failure strain $\left(\varepsilon_{\mathrm{f}}>0.5\right.$; see Table 1$)$ at room temperature at these strain rates.

\section{Experimental}

Two techniques were employed in this investigation. The first was a larger version of the direct impact Hopkinson bar (DIHB) originally developed by Gorham /5/ for testing materials at strain rates in the range $10^{4} \mathrm{~s}^{-1}$ to $10^{5} \mathrm{~s}^{-1}$ ), the analysis used to calculate stress-strain curves directly from DIHB data being published by Pope \& Field $/ 6 /$. The second technique was a drop-weight apparatus modified so as to be able to take high-speed photographic sequences (interframe time $7 \mu \mathrm{s}$ ) of the deformation $7 /$.

Four of the polymers (polycarbonate (PC), noryl, nylon 6, and nylon 66) were available as injection moulded discs $5 \mathrm{~mm}$ in diameter and $2 \mathrm{~mm}$ thick. The other polymers tested were either punched from commercially available sheet or from discs parted from rod. The specimens formed by this method were $6.4 \mathrm{~mm}$ diameter and $2.5 \mathrm{~mm}$ thick.

For the low temperature work, the specimens were cooled by dropping them into a bath of liquid nitrogen (the rate of cooling has been shown by Agrawal et al. /8/ to have very little effect on the fracture toughness or flow stress of PC). Their subsequent testing gave rise to a number of problems. Ideally the DIHB should be fitted with an environmental chamber to maintain the specimens at a known temperature. However, this would need to be thermally shielded from the high-gain semiconductor strain gauges used to record the force-time pulse as these are temperature sensitive. Another problem would be that a thermal 
gradient complicates the analysis of a bar's elastic response and makes obtaining an accurate stress-strain curve from the recorded force pulse more difficult $19 \%$. So for this study, the specimens were simply transferred from the liquid nitrogen bath to the DIHB and the test carried out within five seconds. Care was taken to carry the specimens across with a drop of liquid nitrogen resting on them to stabilise the temperature. An experiment in which a thermocouple was placed in a hole drilled into a specimen showed that the temperature rose to $c a .130 \mathrm{~K}$ five seconds after removal from the bath.

Obtaining high-speed photographic sequences of the rapid deformation of polymer discs at 100K, required several alterations to the apparatus and experimental technique. Firstly, the specimen sits on a transparent toughened glass anvil and must be kept cold until the camera, which is of the rotating mirror type, is up to speed. This requires the anvil itself to be cold, and to achieve this the anvil has a paper collar constructed around it so that a pool of liquid nitrogen can be formed on its top surface. In order to prevent frosting on the lower surface of the anvil, the space beneath is sealed and dried for about an hour before the anvil is cooled, the drying agent being phosphorus pentoxide. The liquid nitrogen must all be allowed to boil away else the specimen gets knocked around and cannot be positioned accurately. The drop-weight is released within five seconds of the cessation of boiling. A thermocouple measurement showed that the temperature rise during this time was no more than $10 \mathrm{~K}$.

\section{Results}

With the one exception of polycarbonate, all the polymers tested had smaller failure strains at $100 \mathrm{~K}$ than at $300 \mathrm{~K}$ (see Table 1). Some polymers fractured before they yielded (figure 1), but those that yielded before they fractured exhibited, as expected $/ 10 /$, a significantly higher flow stress at the lower temperature (figures 2-4 and Table 1). Some of these did not fracture within the time window $(285 \mu \mathrm{s})$ of the DIHB (figure 2 ). Their failure strain $\varepsilon_{\mathrm{f}}$ could only be determined by high-speed photography.

\section{Discussion}

Table 1 shows that where a direct comparison can be made, the photographic record usually gave higher values of $\varepsilon_{\mathrm{f}}$ than the DIHB. An exception to this was high density polyethylene (HDPE) which was not observed to fail at $100 \mathrm{~K}$ up to a natural strain of 0.21 in the DIHB. Possible reasons for the discrepancy in the values of $\varepsilon_{\mathrm{f}}$ obtained by these two methods include: (i) the values of the failure strain quoted from the DIHB are averages from four or five stress-strain curves whereas the values quoted from photographic measurements were obtained from a single measurement. Several polymers showed considerable variation in failure behaviour from test to test (e.g. figures 3, 4), the DIHB stress-strain curves almost reaching the strain-to-failure seen by photography in some cases (figure 4). (ii) The load carried by the specimen might fall due to, for example, internal cracking before there was any visible sign of failure in the photographic record.

The failure strain was expected to fall as the temperature is lowered at a given strain rate $/ 11 /$, though predicting whether a given polymer will yield before it fractures or vice versa at a given temperature and strain rate is far more difficult to predict as the fracture strain changes rapidly in the vicinity of secondary mechanical relaxation peaks $/ 11 \%$. The polymers investigated differed markedly in their mode of failure, particularly at room temperature (figures 5-8). The results reported here were part of a phenomenological study to establish the feasibility of the experimental technique: they were not intended to distinguish between various constitutive relations. More thorough investigations over a wide range of temperatures and strain rates of one or two amorphous polymers (PC and PMMA in torsion, $/ 11 / ; \mathrm{PC}$ in compression $/ 12 /$, /13/) have shown that simple activated rate theories are quite adequate for most engineering purposes.

\section{References}

11 S.M. Walley, J.E. Field, G.M. Swallowe, S.N. Mentha, J. Phys. (France) Colloq. 46-C5 (1985) 607-616.

$12 /$ G.M. Swallowe, J.E. Field, L.A. Horn, J. Mater. Sci. 21 (1986) 4089-4096.

B/ S.M. Walley, J.E. Field, P.H. Pope, N.A. Safford, Phil. Trans. R. Soc. Lond. A328 (1989) 1-33.

/4/ S.M. Walley, J.E. Field, P.H. Pope, N.A. Safford, J. Phys. III (submitted for publication).

15/ D.A. Gorham, Inst. Phys. Conf. Ser. 47 (1980) 16-24.

$16 /$ P.H. Pope, J.E. Field, J. Phys. E: Sci. Instrum. 17 (1984) 817-820.

II S.N. Heavens, J.E. Field, Proc. R. Soc. Lond. A338 (1974) 77-93.

/8/ C.M. Agrawal, K.J. Heater, A.J. Hill, J. Mater. Sci. Letts 8 (1989) 1414-1415.

19/ N.E. El Bounia, J.P. Robert-Amouil, F. Gillaizeau, J-L. Lataillade. In Impact Loading and Dynamic Response of Materials 2 (1988), ed. C.Y. Chiem, H-D. Kunze, L.W. Meyer, pp 631-637, publ. DGM Informationgesellschaft Verlag.

/10/ I.M. Ward, The Mechanical Properties of Solid Polymers, 2nd edn, chapter 11, publ. Wiley, Chichester. 
/11/ N.A. Fleck, W.J. Stronge, J.H. Liu, Proc. R. Soc. Lond. A429 (1990) 459-479.

112/ P. Steer, Thèse de Docteur en Science des Matériaux, no. 16 (1985), Université de Bordeaux I.

113/ P. Steer, F. Rietsch, J-L. Lataillade, A. Marchand, N-E. El Bounia, J. Phys. (France) Colloq. 46-C5 (1985) 415-423.

TABLE 1

Response of a number of polymers to deformation at a strain rate of $10^{3} \mathrm{~s}^{-1}$ at temperatures of $c a .100 \mathrm{~K}$ and $300 \mathrm{~K}$

Polymer

Dry N6
Moist N6
Dry N66
Moist N66
PC

Noryl

PBT

PVDF

PP

HDPE

PET

PTFE

PVC

Acetal

PES

PEEK

ABS
Temperature of $100 \mathrm{~K}$

\section{Response}

Brittle

Brittle

Brittle

Brittle

Ductile

Ductile

Brittle

Brittle

Brittle

Ductile

Brittle

Ductile

Brittle

Brittle

Ductile

Ductile

Brittle

$$
\sigma_{\mathbf{y}} / \mathbf{M P a}
$$

280

300

310

290

185

(strain softens) 210

(strain softens)

$\mathrm{NY}$

NY

140

130

NY

140

(yield just reached)

NY

NY

170

(strain softens)

Yield not reached NY

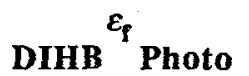

$\begin{array}{ll}0.05 & 0.43\end{array}$

$0.1 \quad 0.06$

$0.13 \quad 0.25$

$\begin{array}{ll}0.12 & 0.42\end{array}$

NF 1.1

NF $\quad 0.19$

0.05

0.06

0.24

0.4

0.04

NF

0.05

NF

0.05

0.12

0.12

0.32

0.56

0.2

0.03

NF

NF

0.04

0.12
Temperature of $300 \mathrm{~K}$

$\sigma_{\mathbf{y}} / \mathbf{M P a}$

$$
144
$$

105

154

123

108

(strain softens)
126

(strain softens)

105

(strain softens)

133

(strain softens)

59 NF

43

136

19

(strain hardens)

128

(strain softens)

$\begin{array}{lcl}0.21 & 133 & 0.55\end{array}$

0.3 (tearing) 121

0.8 (internal cracking)

$0.25 \quad 123$

61

NF

1.1 (tearing)

Note: all the polymers tested in these experiments were ductile at room temperature $(300 \mathrm{~K})$ that is to say they exhibited either no failure strain (indicated by "NF") or a very large one. At $100 \mathrm{~K}$, some were so brittle that no yield stress could be identified; this is indicated by "NY". Some, on the other hand, had a failure strain at $100 \mathrm{~K}$ so large that they did not fail within the time window of the Hopkinson bar. Again this is indicated by "NF". Their failure strains could, however, be determined by high speed photography.
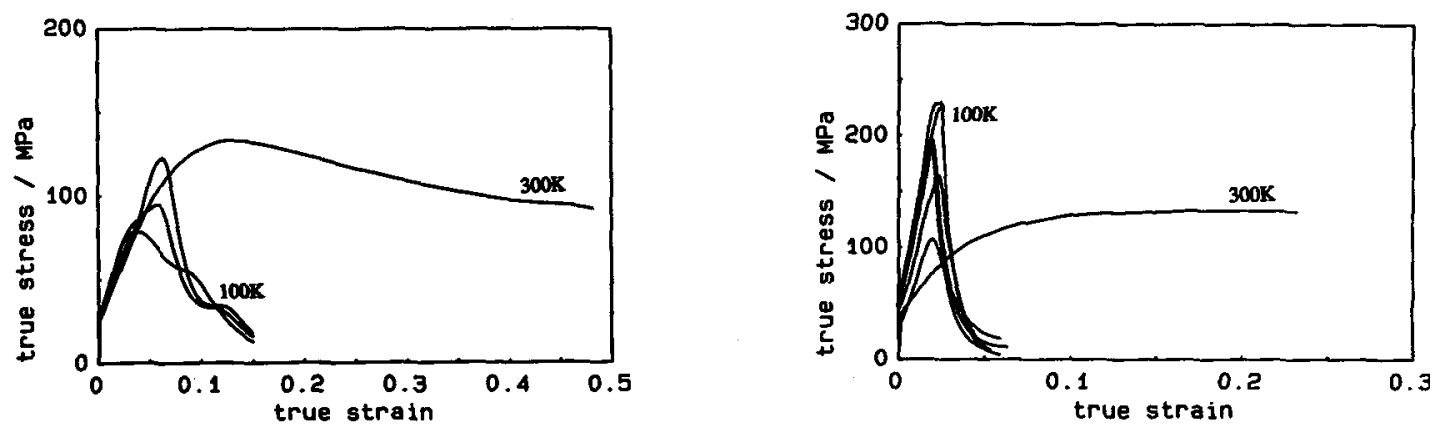

(a)

Figure 1. Compressive stress-strain curves of (a) polyvinylidene difluoride (PVDF) and (b) polyoxymethylene (Acetal) at a strain rate of $2.5 \times 10^{3} \mathrm{~s}^{-1}$ at $100 \mathrm{~K}$ and $300 \mathrm{~K}$. 

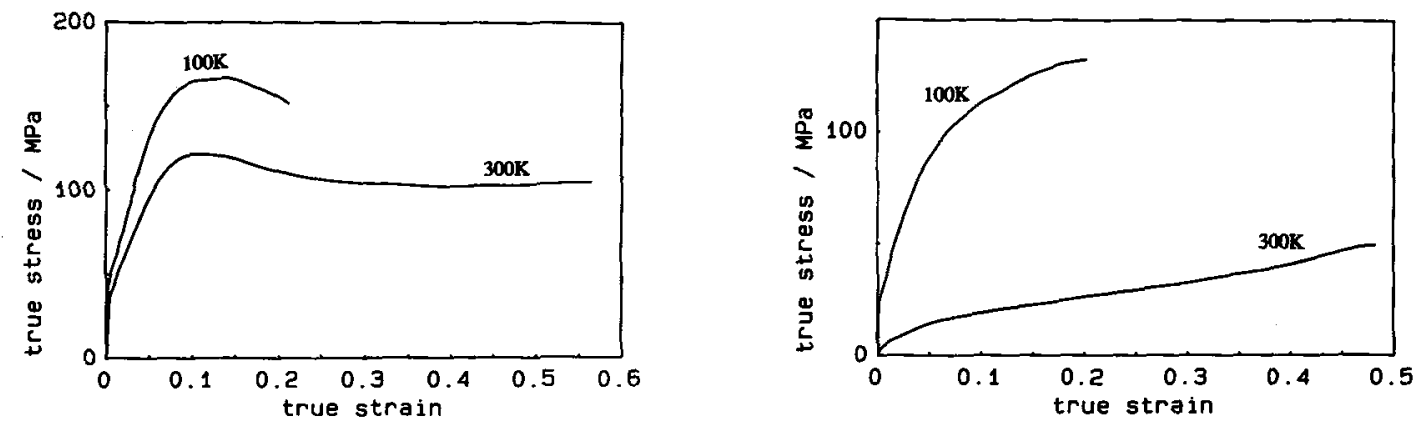

(a)

(b)

Figure 2. Compressive stress-strain curves of (a) polyethersulphone (PES)

and (b) polytetrafluoroethylene (PTFE) at a strain rate of $2.5 \times 10^{3} \mathrm{~s}^{-1}$ at $100 \mathrm{~K}$ and $300 \mathrm{~K}$.
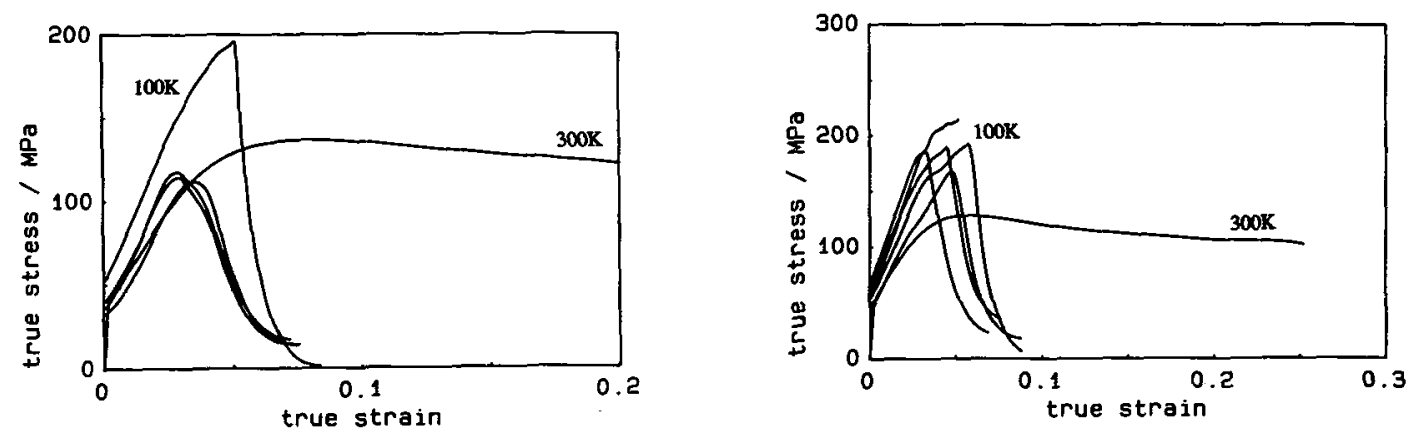

(a)

(b)

Figure 3. Compressive stress-strain curves of (a) polyethylene teraphthalate (PET) and $(b)$ polyvinylchloride $(P V C)$ at a strain rate of $2.5 \times 10^{3} \mathrm{~s}^{-1}$ at $100 \mathrm{~K}$ and $300 \mathrm{~K}$.
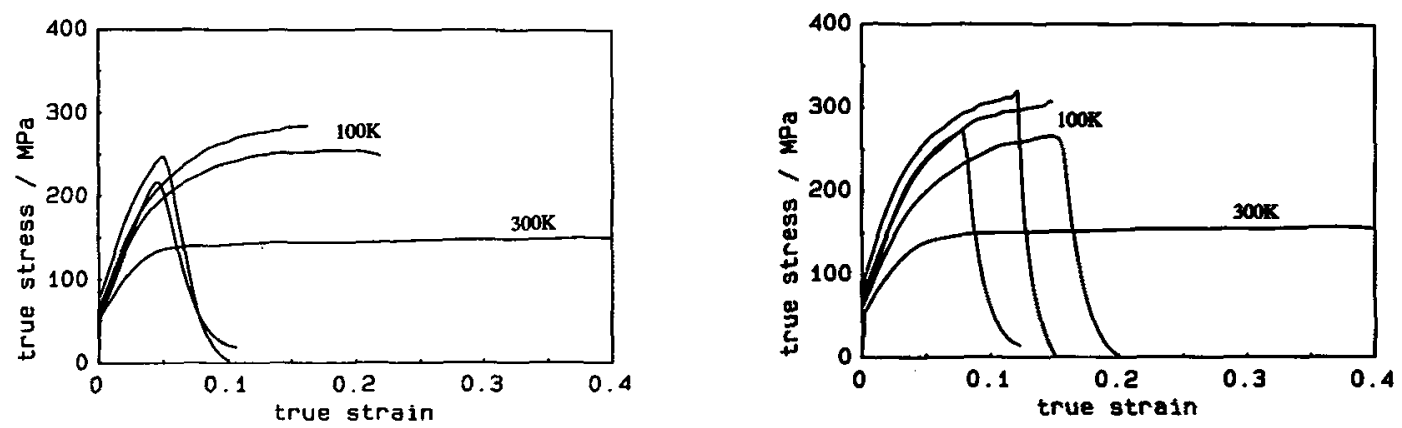

(a)

Figure 4. Compressive stress-strain curves of (a) dry nylon 6 and (b) dry nylon 66 at a strain rate of $2.5 \times 10^{3} \mathrm{~s}^{-1}$ at $100 \mathrm{~K}$ and $300 \mathrm{~K}$. 

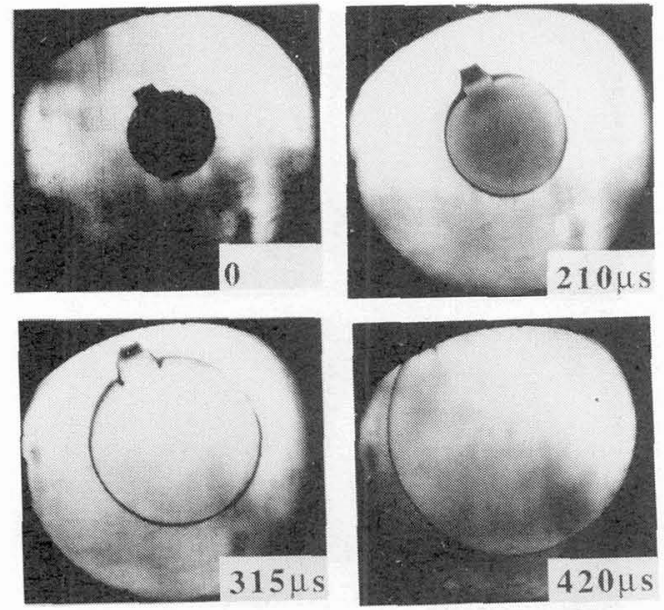

(a)
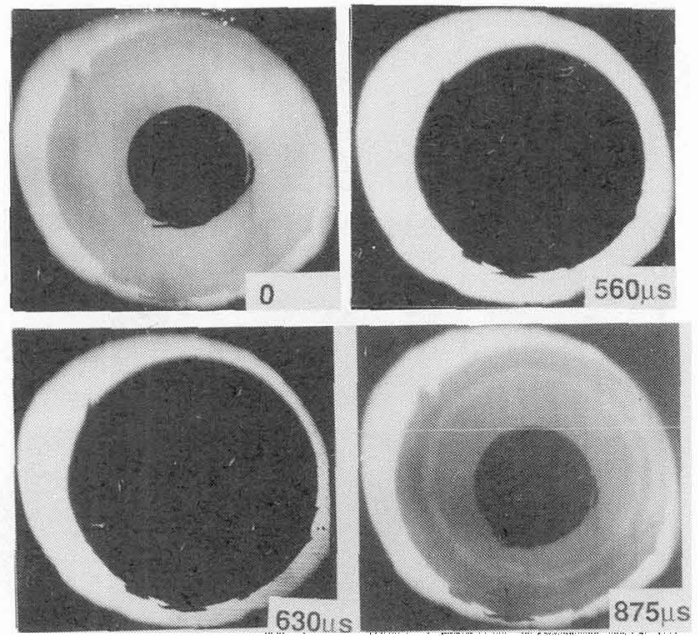

(a)
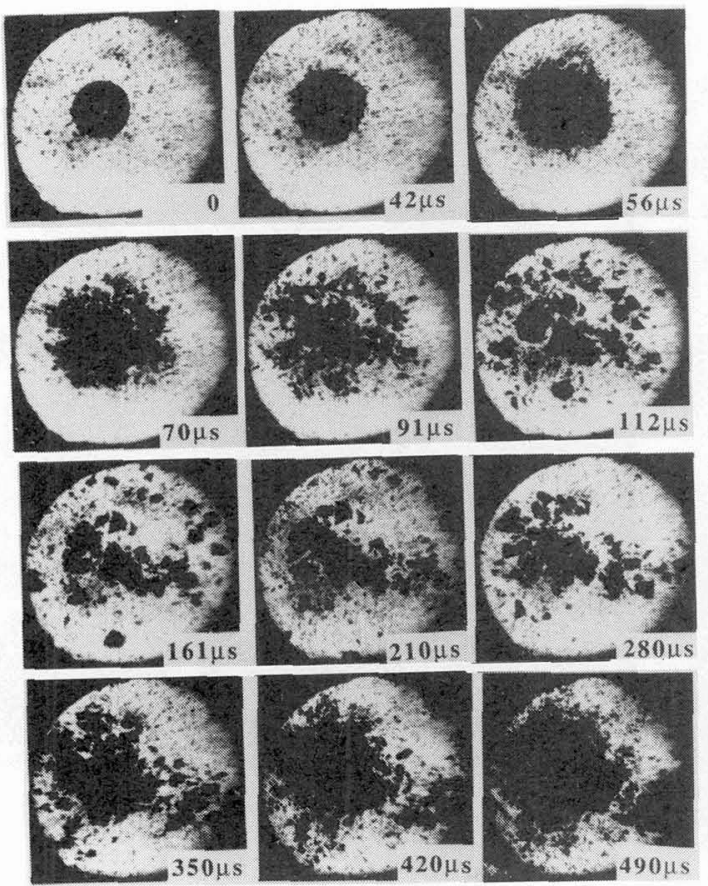
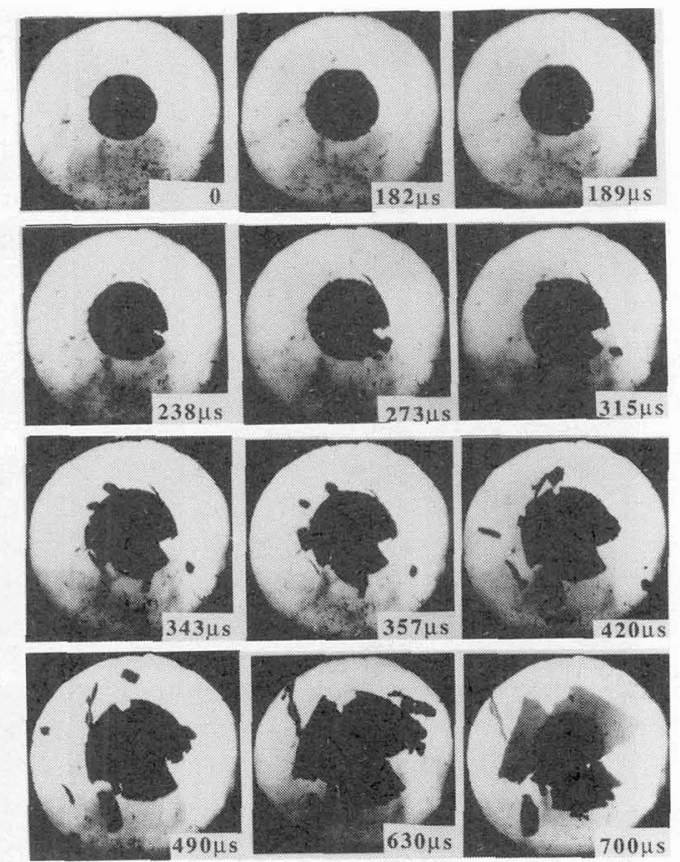

(b)

Figure 5. Selected frames from a high-speed photographic sequence of the rapid deformation of $5 \mathrm{~mm}$ diameter $2 \mathrm{~mm}$ thick moist nylon 66 discs at (a) $300 \mathrm{~K}$ and (b) $100 \mathrm{~K}$.
Figure 6. Selected frames from a high-speed photographic sequence of the rapid deformation of $6.35 \mathrm{~mm}$ diameter $2.5 \mathrm{~mm}$ thick polyetheretherketone (PEEK) discs at (a) $300 \mathrm{~K}$ and (b) $100 \mathrm{~K}$. 

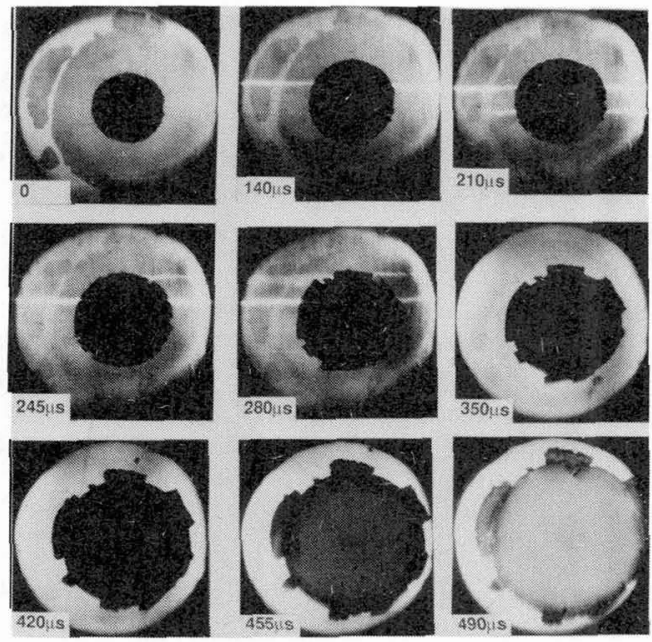

(a)
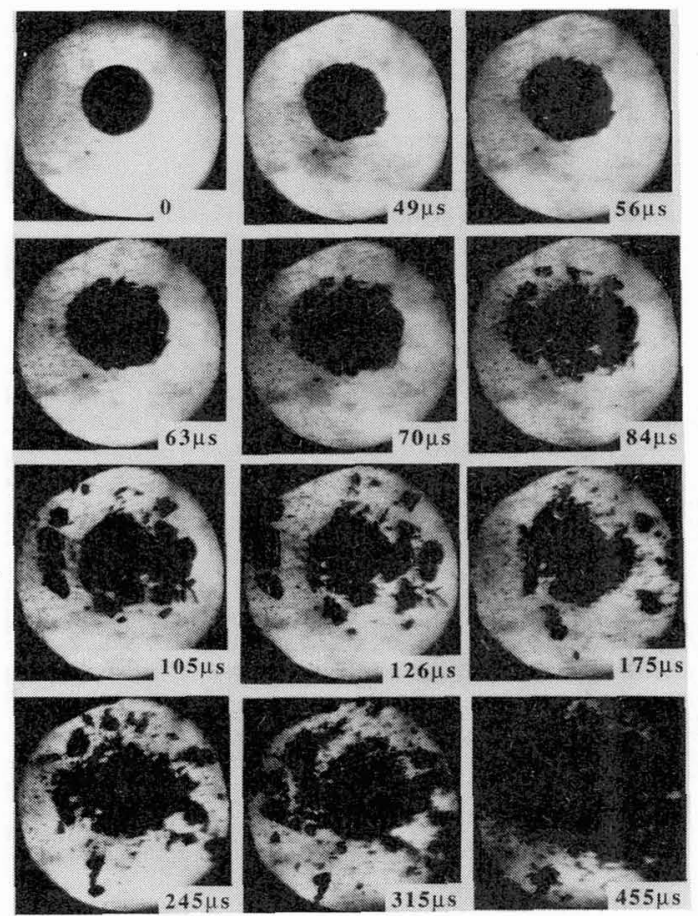

(b)
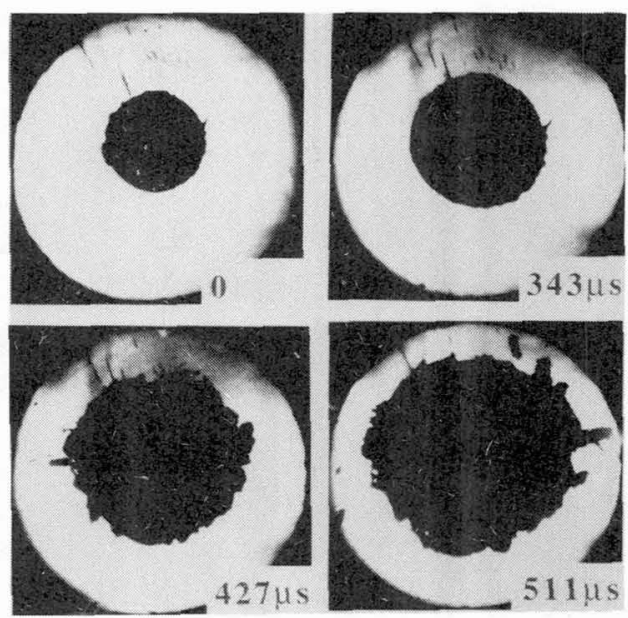

(a)
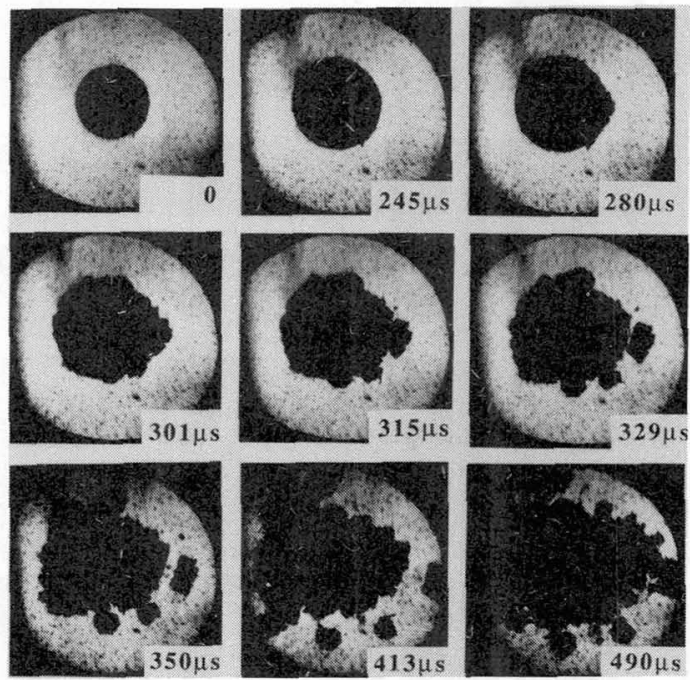

(b)
Figure 7. Selected frames from a high-speed photographic sequence of the rapid deformation of $6.35 \mathrm{~mm}$ diameter $2 \mathrm{~mm}$ thick acetal discs at (a) $300 \mathrm{~K}$ and (b) $100 \mathrm{~K}$.
Figure 8. Selected frames from a high-speed photographic sequence of the rapid deformation of $6.35 \mathrm{~mm}$ diameter $2.4 \mathrm{~mm}$ thick PTFE discs at (a) $300 \mathrm{~K}$ and (b) $100 \mathrm{~K}$. 